\title{
Bone Marrow Mesenchymal Stem Cells Carrying FANCD2 Mutation Differ from the Other Fanconi Anemia Complementation Groups in Terms of TGF- $\beta 1$ Production
}

\author{
Ilgin Cagnan ${ }^{1}$ - Aysen Gunel-Ozcan ${ }^{1}$ (1) - Fatima Aerts-Kaya ${ }^{1} \cdot$ Najim Ameziane $^{2}$ - Baris Kuskonmaz ${ }^{3}$. \\ Josephine Dorsman ${ }^{2} \cdot$ Fatma Gumruk ${ }^{4}$ Duygu Uckan ${ }^{1,3}$
}

Published online: 15 December 2017

๑) Springer Science+Business Media, LLC, part of Springer Nature 2017

\begin{abstract}
Transforming growth factor beta (TGF- $\beta$ ) secretion from cells in the bone marrow (BM) niche affects hematopoietic stem cell (HSC) fate and has a cardinal role in HSC quiescence. BM mesenchymal stem cells (BM-MSCs), a component of the BM niche, may produce abnormal levels of TGF- $\beta$ in Fanconi anemia (FA) and may play a role in bone marrow failure. Here, we molecularly and cellularly characterized FA BM-MSCs by addressing their immunophenotype, proliferation- and differentiation- capacity, reactive oxygen species (ROS) production, senescence activity as well as expression and secretion levels of TGF- $\beta$ isoforms. In ten FA patients, mutations were detected in FANCA $(n=7), F A N C G(n=1)$ and FANCD2 $(n=2)$ genes. The immunophenotype, with the exception of CD29, and differentiation capacity of FA BM-MSCs were similar to healthy donors. FA BM-MSCs showed decreased proliferation, increased ROS level and an arrest in G2 following DEB treatment. $\beta$-galactosidase staining indicated elevated senescence of $F A N C D 2$-deficient cells. FA BM-MSCs displayed TGF- $\beta 1$ mRNA levels similar to donor BM-MSCs, and was not affected by DEB treatment. However, secretion of TGF- $\beta$ was absent in FA-D2 BM-MSCs. Absence of TGF- $\beta$ secretion may be related to early onset of senescence of the FANCD2-deficient BM-MSCs. The proliferative response of FA-D2 BM-MSCs to rTGF- $\beta 1$ was not different from FANCA-deficient and donor cells and raises the possibility that rTGF- $\beta 1$ may reverse the senescence of the FANCD2-deficient BM-MSCs which needs to be investigated further.
\end{abstract}

Keywords TGF-BETA $\cdot$ Bone marrow $\cdot$ Mesenchymal stem cells $\cdot$ Fanconi anemia $\cdot$ FANCD2

Electronic Supplementary Material The online version of this article (https://doi.org/10.1007/s12015-017-9794-5) contains supplementary material, which is available to authorized users.

Aysen Gunel-Ozcan agozcan@hacettepe.edu.tr

1 Department of Stem Cell Sciences, Institute of Health Sciences, Center for Stem Cell Research and Development, Hacettepe University, 06100, Sihhiye, Ankara, Turkey

2 Department of Clinical Genetics, VU University Medical Center, Amsterdam, The Netherlands

3 Department of Pediatrics, Division of Bone Marrow Transplantation Unit, Faculty of Medicine, Hacettepe University, Ankara, Turkey

4 Department of Pediatric Hematology, Faculty of Medicine, Hacettepe University, Ankara, Turkey

\section{Introduction}

Hematopoietic stem cell (HSC) and progenitor numbers are in a delicate balance, regulated by complex signaling [1]. In the bone marrow (BM), homeostasis of hematopoietic cells is orchestrated by intrinsic signaling pathways, as well as crosstalk between the HSCs and its niche components, such as BM stroma [2]. Multipotent mesenchymal stem cells (MSCs) are important components of the BM stroma [3], and may affect the balance between HSC self-renewal and differentiation. Impairment of the crosstalk between HSC and the BM stromal cells can lead progressive bone marrow failure (BMF) and hematopoietic malignancies [4].

Accumulation of DNA damage causes hematopoietic aging throughout life and is accelerated in DNA repair deficiencies, such as Fanconi anemia (FA) [5, 6]. FA (MIM 227,650) is a hereditary disease, which is classified 
according to at least 22 complementation groups and can be inherited in an autosomal recessive (FA-A, -C, -D1, -D2, -E, -F, -G, -I, -J, -L, -M, -N, -O, -P, -Q, -S, -T, -U, -V, -W), $\mathrm{X}$-linked (FA-B), or autosomal dominant manner (FA-R) $[7,8]$. FA proteins are involved in complex pathways to maintain genome integrity $[9,10]$. FA gene mutations affect quiescent hematopoietic stem cells (HSC) and their progenitors, which eventually cause acute myeloid leukemia (AML) or aplastic anemia due to bone marrow failure (BMF) [6, 11]. HSC in a disease state may imprint function of niche cells [2]. The treatment of choice for BMF in FA patients is bone marrow transplantation (BMT), which may aid in restoring the HSC vascular and perivascular niche. However, BMT does not restore osteoblastic niche [12]. After BMT, secondary solid tumors are increased and metabolic disturbances are frequently seen [13, 14]. Comparative studies of BM-MSCs in healthy and disease conditions may help our understanding of the role of niche cells in HSC dynamics and provide insight into the disease pathogenesis.

To date, few studies reported similar immunophenotypes and differentiation capacity of FA-derived BMMSCs and donor cells $[15,16]$. However, FA BM-MSCs have been shown to have decreased proliferation and increased senescence $[15,16]$, which may disturb its support of HSC maintenance and may have a role in BMF by either juxtacrine or paracrine signaling. A recent study investigating novel therapeutic targets for BMF demonstrated hyperactive transforming growth factor beta (TGF$\beta$ ) signaling in FA HSCs and overexpression of $T g f-\beta 1$ in Fancd $2^{-/-}$mice hematopoietic stem and progenitor cells (HSPCs) [17].

Effects of $T G F-\beta$ signaling in BM are wide ranged, from controlling HSC cell fate to remodeling of the BM niche $[18,19]$. Autocrine signaling of TGF- $\beta$ in HSC is apparent [20] and very recent in vivo studies in mice have begun to unveil the role of TGF- $\beta$ in Fanconi anemia BM $[17,21]$. The paracrine influence from BM-MSCs, as part of the BM microenvironment, still needs to be elucidated to understand BMF in Fanconi anemia. Here, we characterized FA patient derived BM-MSCs at the molecular and cellular level by addressing their immunophenotypes, proliferation and differentiation capacities, as well as expression and secretion levels of transforming growth factor beta (TGF- $\beta$ ) isoforms in comparison to healthy donor BM-MSCs.

\section{Materials and Methods}

\section{Patients and Controls}

Cryopreserved BM- mononuclear cells (BM-MNCs) from FA patients obtained at Hacettepe University Pediatric Hematology Bone Marrow Transplantation unit were used for isolation of BM-MSCs. Patients (designated as HUSCS-FA01-12; $n=12$ ) were diagnosed based on clinical manifestations (Table 1; see Supplementary Table 1 for blood counts of patients) and the presence of a positive DEB test. Healthy BMT donors (designated as HUSCSD01-16; $\mathrm{n}=16$ ) served as controls. The study complied with the principles of the Declaration of Helsinki (updated 2008; http://www.wma.net/en/30publications/10policies/ b3/index.html) and was approved by the Local Ethical Committee (Number 14, 24/08/2009) and Hacettepe University Non-interventional Clinical Research Ethics Board (GO 14/403 - 12, 23/07/2014). Informed consent was obtained from donors and FA patients enrolled in this study. The mean age range of patients was $10.3 \pm 4.1$ years; of FA family donors was $10.9 \pm 5.2$ years; and of unrelated donors was $12.8 \pm 8.9$ years (Table 2 ).

\section{Mutational Analysis of the FA Individuals}

Mutation screening of the FA genes was initially performed according to the algorithm described earlier [22]. The screening starts with parallel analysis of large deletions and complete sequencing of the FANCA gene by Multiplex Ligation-Dependent Probe Amplification (MLPA) [23] and Sanger sequencing, respectively. For cases negative for known mutations in the FANCA gene, next generation sequencing of the coding regions and exon-intron boundaries for all known FA genes were performed. The protocol and primers for Sanger sequencing and probe details for FANCA gene were previously outlined [22].

The screening of the known FA genes by next generation sequencing was performed on a Miseq Illumina sequencer after enrichment with a custom HaloPlex Target Enrichment kit (Agilent, USA), as previously reported [24]. The Haloplex kit was designed to detect alterations in the $F A N C-A$, $-B,-C,-D 2,-E,-F,-G,-I,-L,-M, B R C A 1, B R C A 2, B R I P 1$, ERCC4, PALB2, RAD51, and SLX4 genes. The procedure and the identified mutations for each FA individual are depicted in Table 3.

\section{Isolation, Culture and Characterization of BM-MSCs}

Details of isolation and culture of BM-MSCs were described previously [27]. BM-MSCs were cultured in DMF10 medium containing 60\% Dulbecco's modified Eagle's medium-low glucose (DMEM-LG; GIBCO, UK) and 40\% MCDB-201 medium (Sigma-Aldrich, USA) supplemented with $10 \%$ heat-inactivated fetal bovine serum (GIBCO), 100 $\mathrm{U} / \mathrm{mL}$ penicillin and $100 \mu \mathrm{g} / \mathrm{mL}$ streptomycin, and $2 \mathrm{mM}$ L-glutamine (Biochrom AG, Germany). Cell cultures were 
Table 1 Characteristics of Fanconi anemia patients

\begin{tabular}{|c|c|c|c|c|}
\hline Sample ID & Anemia & DEB Test & $\begin{array}{l}\text { Cytogenetic/ } \\
\text { peripheral blood dysplasia }\end{array}$ & Clinical Features \\
\hline HUSCS-FA01 & + & + & 46, XY & $\begin{array}{l}\text { Hypospadias, cryptorchidism, deviation to right at } \\
\text { IVS and slight enlargement of left ventricle }\end{array}$ \\
\hline HUSCS-FA02 ${ }^{\#}$ & + & + & $10 \mathrm{p}$ & Cafe au lait and hyperpigmentation \\
\hline HUSCS-FA03 & + & + & $\begin{array}{l}\text { Out of } 19 \text { metaphases, } 2 \text { showed hypodiploidy } \\
\text { and } 1 \text { showed } 8+\text { mar }\end{array}$ & $\begin{array}{l}\text { Microphthalmia, hyperpigmentation, left kidney } \\
\text { agenesis, hypothyroidism, bilateral hearing loss }\end{array}$ \\
\hline HUSCS-FA04 & + & + & $\begin{array}{l}\text { Out of } 10 \text { metaphases, } 7 \text { showed non-clonal } \\
\text { hypodiploidy and no structural anomalies }\end{array}$ & Cafe au lait, left kidney agenesis and osteopenia \\
\hline HUSCS-FA05 & + & + & $\begin{array}{l}17 \text { metaphases were structurally normal. } 3 \text { meta- } \\
\text { phases showed non-clonal structural alterations } \\
\text { indicating chromosomal instability }\end{array}$ & $\begin{array}{l}\text { Microcephaly, microphthalmia, ptosis, cafe au lait } \\
\text { and hyperpigmentation }\end{array}$ \\
\hline HUSCS-FA06 ${ }^{*}$ & + & - & $46, X Y$ & $\begin{array}{l}\text { Extremity anomalies, right ectopic kidney, right } \\
\text { hydroureteronephrosis, right extra renal pelvis } \\
\text { and patent ductus arteriosus }\end{array}$ \\
\hline HUSCS-FA07* & + & - & $\begin{array}{l}17 \text { metaphases were both structurally and quanti- } \\
\text { tatively normal. } 2 \text { metaphases showed add(7)(q) }\end{array}$ & $\begin{array}{l}\text { Microcephaly, microphthalmia, cafe au lait, hyper- } \\
\text { pigmentation, left ectopic kidney and growth } \\
\text { retardation }\end{array}$ \\
\hline HUSCS-FA08 & + & + & $46, X Y$ & $\begin{array}{l}\text { Extremity anomalies, unilateral kidney agenesis, } \\
\text { atrial septal defect, ventricular septal defect, } \\
\text { hypothyroidism and cryptorchidism }\end{array}$ \\
\hline HUSCS-FA09.a ${ }^{* *}$ & + & + & 46, XX & $\begin{array}{l}\text { Microcephaly, hyperpigmentation, left kidney } \\
\text { agenesis, growth retardation and hyperglycemia }\end{array}$ \\
\hline HUSCS-FA09.b ${ }^{* *}$ & + & + & $\begin{array}{l}11 \mathrm{q} 23 \text { deletion at } 1 \text { metaphase and hypodiploidy } \\
\text { at } 2 \text { metaphases }\end{array}$ & $\begin{array}{l}\text { Hydrocephaly, microphthalmia, ptosis, hyper/ } \\
\text { hypopigmentation, cafe au lait, cortical cyst and } \\
\text { osteoporosis }\end{array}$ \\
\hline HUSCS-FA10 & - & + & $\begin{array}{l}\text { out of } 15 \text { metaphases, } 1 \text { had del(1)(q11qter) and } 5 \\
\text { had non-clonal hypodiploidy. + }\end{array}$ & $\begin{array}{l}\text { Growth retardation, microcephaly, Cafe au lait and } \\
\text { hyperpigmentation }\end{array}$ \\
\hline HUSCS-FA11 & + & + & $\begin{array}{l}\text { out of } 15 \text { metaphases, } 6 \text { had der( } 4) t(1 ; 4) \\
(\mathrm{q} 11 ; \mathrm{p} 16) ; \text { indication of partial trisomy } 1 \mathrm{q}\end{array}$ & $\begin{array}{l}\text { Microcephaly, microphthalmia, hyperpigmentation } \\
\text { and mitral valve prolapse }\end{array}$ \\
\hline
\end{tabular}

DEB Test, Diepoxybutane Test; F, Female; M, Male; +, present; -, absent;

*DEB Test results of FA-06 and FA-07 do not support International Fanconi Anemia Registry (IFAR) criteria (The Rockefeller University, 2013);

\#DEB test was positive for the sister of HUSCS-FA02 diagnosed as leukemia.

${ }^{* *}$ HUSCS-FA09.a and HUSCS-FA09.b are siblings

passaged at least three times prior to further experiments, unless otherwise indicated.

\section{Immunophenotyping BM-MSCs}

Immunophenotyping of donors and patients was performed by flow cytometry using antibodies against mesenchymal and hematopoietic cell surface proteins, as described [27]. Directly labelled cell surface antibodies against CD29, CD44, CD73, HLA-ABC, CD90, CD105, CD106, CD140b, CD144, CD146, CD166, CD200, CD271 were used to detect cells from mesenchymal stromal cell origin. Endothelial cell marker CD31 and hematopoietic cell markers CD45, CD14, HLA-DR, CD34 were used to exclude cells of hematopoietic origin. A general stem cell marker, CD133 was also used for immunophenotyping. Details of antibodies used are given in Supplementary Table 2.

\section{Assessment of Differentiation Capacity of BM-MSCs}

BM-MSCs were cultured in adipogenic and osteogenic induction media to assess their differentiation capacity. Details of adipogenic and osteogenic differentiation protocols were described previously [27].

\section{Population Doubling Analysis of BM-MSCs}

The proliferative capacity of passage 3-7 (P3-7) of BM-MSCs derived from patients $(n=5)$ and donors 
Table 2 Overview of donors and Fanconi anemia patients

\begin{tabular}{|c|c|c|c|}
\hline Donor ID & $\begin{array}{l}\text { Gender/ } \\
\text { Age (Years) } \psi\end{array}$ & FA Patient ID & $\begin{array}{l}\text { Gender/ } \\
\text { Age (Years)y }\end{array}$ \\
\hline HUSCS-D01* & $\mathrm{F} / 14$ & HUSCS-FA01 & $\mathrm{M} / 9$ \\
\hline HUSCS-D02* & $\mathrm{M} / 6$ & HUSCS-FA02 & $\mathrm{F} / 6$ \\
\hline HUSCS-D03* & $\mathrm{F} / 2$ & HUSCS-FA03 & $\mathrm{F} / 12$ \\
\hline HUSCS-D04* & $\mathrm{M} / 10$ & HUSCS-FA04 & M / 14 \\
\hline HUSCS-D05* & $\mathrm{F} / 15$ & HUSCS-FA05 & M / 14 \\
\hline HUSCS-D06* & $\mathrm{M} / 13$ & HUSCS-FA06 & $\mathrm{M} / 9$ \\
\hline HUSCS-D07* & $\mathrm{M} / 16$ & HUSCS-FA07 & $\mathrm{F} / 5$ \\
\hline HUSCS-D08 & $\mathrm{M} / 2$ & HUSCS-FA08 & $\mathrm{M} / 5$ \\
\hline HUSCS-D09 & $\mathrm{M} / 10$ & HUSCS-FA09.a & $\mathrm{F} / 13$ \\
\hline HUSCS-D10 & $\mathrm{F} / 18$ & HUSCS-FA09.b & M / 6 \\
\hline HUSCS-D11 & M / 19 & HUSCS-FA10 & M / 17 \\
\hline HUSCS-D12 & $\mathrm{F} / 3$ & HUSCS-FA11 & F/ 13 \\
\hline HUSCS-D13 & $\mathrm{F} / 25$ & & \\
\hline HUSCS-D14 & $\mathrm{F} / 24$ & & \\
\hline HUSCS-D15 & $\mathrm{M} / 7$ & & \\
\hline HUSCS-D16 & $\mathrm{M} / 7$ & & \\
\hline
\end{tabular}

*Indicates FA patient donors; $\psi$, Age of Donors and FA patients at the day of bone marrow transplantation

$(n=4)$ were compared. Cells were counted at every passage using Trypan blue and population doublings (PD) were calculated. PD was determined by the following formula $\log 10$ (fold expansion) $\div \log 10$ (2) where fold expansion $=$ cell harvested $\div$ cell seeded. 16667 cells per well of six well plates were seeded and five technical replicates were performed for each independent sample. Finally, cumulative (c) PD was calculated [28].

\section{Assessing Senescence Associated Beta-Galactosidase (SA- $\beta$-gal) Activity in BM-MSCs}

Cellular senescence of P3 and P6 BM-MSCs from patients $(n=3)$ and donors $(n=2)$ was compared using the SA- $\beta$-gal Staining Kit (Cell Signaling Technology, USA) according to the manufacturer's instructions. Images were obtained using an inverted microscope (Olympus CKX41; Olympus, Japan). Quantification of senescent cells was performed by counting the number positively stained and unstained cells using 100X magnified images (i.e. two technical replicates per sample) by Cell Counter plugin in ImageJ software (NIH, USA). Then, the percentage of positive cells was calculated by the following formula; $=($ positive cell count $\times 100) \div$ total cell count, where total cell count $=$ positive cell count + unstained cell count.

\section{Determining Reactive Oxygen Species (ROS) Level in BM-MSCs}

CM-H2DCFDA probe (Invitrogen, USA) was used as an indicator of ROS in BM-MSCs obtained from FA patients $(n=4)$ and donors $(n=3)$. Briefly, cells were trypsinized and 5000 cells/well were incubated in $100 \mu \mathrm{L}$ PBS containing $10 \mu \mathrm{M} \mathrm{CM}-\mathrm{H} 2 \mathrm{DCFDA}$ in a $5 \% \mathrm{CO}_{2}$ incubator at $37^{\circ} \mathrm{C}$ for 30 min. BM-MSCs in PBS were used as a negative control. Following incubation, cells were washed in PBS, supernatant was discarded and cell pellets were resuspended in $100 \mu \mathrm{L} /$ well PBS. Fluorescence was measured at an excitation of $485 \mathrm{~nm}$ and emission of $520 \mathrm{~nm}$ using FLUOstar Omega microplate reader (BMG Labtech, Germany). Fluorescence of PBS with or without CM-H2DCFDA was measured and
Table 3 Results from mutational screening of the Fanconi anemia patients for known FA genes

\begin{tabular}{|c|c|c|c|c|}
\hline & & Mutation & & \\
\hline Patient ID & Comp. Group & cDNA Level $^{* * *}$ & Expected Consequence & Reference \\
\hline HUSCS-FA01 & FA-A & del exon $3-5^{\#}$ & Truncation & Novel \\
\hline HUSCS-FA02 & FA-A & c. $427-3 \mathrm{C}>\mathrm{G}$ & Aberrant Splicing & Novel \\
\hline HUSCS-FA03 & FA-A & c. $3586 \mathrm{G}>\mathrm{T}$ & p.Glu1196X & Novel \\
\hline HUSCS-FA04 & FA-A & del exon 1-2 & Truncation & Novel \\
\hline HUSCS-FA05 & FA-A & c. $1229 \mathrm{G}>\mathrm{A}$ & p.Trp410X & Novel \\
\hline HUSCS-FA06 & FA-A & c. $2851 \mathrm{C}>\mathrm{T}$ & p.Arg951Trp & {$[25]$} \\
\hline HUSCS-FA07 & FA-A & c. $2738 \mathrm{~A}>\mathrm{C}$ & p.His913Pro & {$[25]$} \\
\hline HUSCS-FA08 & FA-G & c.1182_1192delinsC & p.(Glu395Trpfs*5) & [26] \\
\hline HUSCS-FA09.a ${ }^{* *}$ & FA-D2 & c. $1766+40 \mathrm{~T}>\mathrm{G}$ & Aberrant Splicing & Novel \\
\hline HUSCS-FA09.b ${ }^{* *}$ & FA-D2 & c. $1766+40 \mathrm{~T}>\mathrm{G}$ & Aberrant Splicing & Novel \\
\hline HUSCS-FA10 & ? & No mutation in known FA genes & NA & NA \\
\hline
\end{tabular}

\footnotetext{
**HUFA09.a and HUFA09.b are siblings;

**** Nomenclature of the variants is based on the cDNA sequence using the following transcripts: FANCA, NM_000135.2, FANCG, NM_004629.1, FANCD2, NM_033084.3;

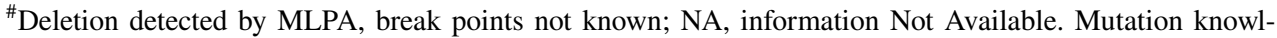
edge of HUSCS-FA04 is based on the patient's file records
} 
used to normalize the data. Five technical replicates per sample were used and the mean of these replicates was used to calculate the normalized fluorescence intensity (FI) using the substraction of normalized FI of medium without cells from normalized FI of cells in the medium in where normalized FI of cells is equal to FI of stained cells minus FI of cells in PBS and normalized FI of no cell control is equal to FI of PBS containing $10 \mu \mathrm{M}$ probe minus FI of PBS.

\section{DEB Treatment of BM-MSCs}

Hallmark of FA cells is the hypersensitivity to DNA interstrand crosslinking (ICL) agents such as diepoxybutane (DEB) leading to late S-G2 checkpoint arrest, DNA damage and genomic instability through high levels of chromosome breaks $[29,30]$. Therefore BM-MSCs were also characterized following DEB treatment. The protocol was adapted from Auerbach (2015) [31]. FA patients $(n=6)$ and donor cells $(\mathrm{n}=3)$ were treated with $0.1 \mu \mathrm{g} / \mathrm{mL}$ DEB (Sigma Aldrich) for 4 days. Flow cytometric analysis was performed for each FA or donor BM-MSC using propidium iodide (PI) staining and measured using a FACSAria (BD Biosciences, USA). BM-MSCs in each cell cycle phase (i.e. dip G1, dip S-phase and dip G2) were analyzed (analysis type: manual, auto-linearity: no ploidy, mode: first cycle is diploid, all cycle events: > 3800, RCS: < 5) using ModFit LT 5.0 software (Verity Software House, Inc., USA) and mean of replicates was calculated.

\section{Gene Expression of FA and Donor BM-MSCs}

RNA isolation, cDNA synthesis and qPCR experiments were performed, as described previously [27]. Briefly, TGF- $\beta 1$ gene expression of FA $(n=7)$ and donor $(n=10)$ cells was normalized against the endogenous house keeping gene, $A C T B$. Following DEB treatment, $T G F-\beta 1$ expression levels of BM-MSCs derived from patients and donors were also determined. Adipogenic (Lipoprotein lipase; $L P L$ ) and osteogenic (tissue-nonspecific isozyme of Alkaline phosphatase; $A L P L$ ) differentiation marker expression levels were determined for differentiation assays.

\section{Active TGF- $\beta 1 / 2 / 3$ Secretion by FA and Donor BM-MSCs}

Active TGF- $\beta 1$, TGF- $\beta 2$ and TGF- $\beta 3$ levels were measured in medium supernatants obtained from 70 to $80 \%$ P3 cultures of FA $(n=9)$ and donor $(n=8)$ cells using the Bio-Plex Pro $^{\text {TM }}$ TGF- $\beta 3$ 3-plex Assay kit (Bio-Rad, USA), following the manufacturer's protocol. Briefly, samples were activated by adding $1 \mathrm{~N}$ hydrochloric acid, followed by incubation for $10 \mathrm{~min}$ at room temperature. Each sample was then neutralized by adding base solution containing 0.5M HEPES and $1.2 \mathrm{~N}$ sodium hydroxide, followed by $1: 16$ dilution using untreated DMF10 medium. For each sample, two technical repeats were studied. Activated DMF10 medium was included as a negative control. FI was determined with the Bioplex MAGPIX multiplex reader (Bio-Rad).

\section{Effect of Recombinant Human TGF- $\beta 1$ Protein Induction on the Proliferative Capacity of BM-MSCs}

Impedance-based real-time cell proliferation of BM-MSCs obtained from FA-A patients $(n=2)$, FA-D2 patients $(n=2)$ and donors $(n=2)$ were determined using the xCELLigence system and analyzed using RTCA software 1.2.1 (Roche Applied Sciences, Germany; ACEA Biosciences, USA). A total of 5000 cells was seeded in each well of a 96-well E-Plate (ACEA Biosciences) and left in a $5 \% \mathrm{CO}_{2}$ incubator at $37^{\circ} \mathrm{C}$ for 30 min to allow BM-MSCs to settle down. Then, the plate was placed onto the device located in a $5 \%$ $\mathrm{CO}_{2}$ incubator at $37^{\circ} \mathrm{C}$ and impedance value of each well, also known as a cell index value, was monitored every $15 \mathrm{~min}$ in a day. BM-MSCs were then treated with 0.1 or $5 \mathrm{ng} / \mathrm{mL}$ recombinant human TGF- $\beta 1$ protein (rTGF- $\beta 1$; BioLegend, USA). Cells in DMF10 media were used as controls. Media were replaced about every $48 \mathrm{~h}$ and the cell index was monitored every $15 \mathrm{~min}$. For each sample, the mean of four technical replicates per condition was assessed. The cell index was normalized to the time point $(26: 41: 34 \mathrm{~h})$ measured just before the rTGF- $\beta 1$ induction. Doubling time of cells during exponential phase was analyzed following the initial addition of the recombinant protein.

\section{Statistical Analysis}

Data obtained from immunophenotyping and cell cycle analysis using flow cytometry were presented as bar graph showing means with standard deviations (SD) constructed using GraphPad Prism 7 (GraphPad Software, Inc., USA). Line graphs showing cPD as well as dot plots displaying ROS production or senescence were constructed using GraphPad Prism 7.

$\Delta \mathrm{Ct}$ method was used in relative quantitative PCR analysis by applying a log transformation to decrease variance heterogeneity across biological samples within groups [32, 33]. When no $\mathrm{Ct}$ value was obtained, the $\Delta \mathrm{Ct}$ value was accepted as 25 . Fold changes were determined by applying a $\log$ transformation to $2^{-\Delta \Delta C t}$ [34]. Dot plots showing mean were constructed using GraphPad Prism 7.

Concentration vs. FI graph of known TGF- $\beta 1 / 2 / 3$ standards $(n=8)$ was calculated using logistic-5PL 
regression analyses. The FI of each sample was interpolated into slopes to find the corresponding concentration and normalized using a negative control to find the actual concentration of TGF- $\beta 1 / 2 / 3$, secreted by the cells. Dot plots showing mean were constructed using GraphPad Prism 7.

Normalized cell index vs. time graph showing BM-MSC proliferation was produced by RTCA software 1.2.1 and bar graphs showing mean doubling time with SD were constructed using GraphPad Prism 7.

Statistical analyses were performed using IBM SPSS Statistics software (Version 24, IBM Corp., USA). To assess differences in cell surface marker expression, $L P L$ or $A L P L$ or $T G F-\beta 1$ expression, fold change in cell cycle phases, ROS production, TGF- $\beta 1 / 2 / 3$ secretion levels and doubling time, the Mann-Whitney U (MWU) test was used. Statistical significance threshold for pairwise analyses was considered as exact $P \leq 0.05$.

\section{Results}

\section{Molecular Classification of the FA Individuals}

Of 10 independent FA individuals, from whom genomic DNA was available in the Hacettepe University DNA biobank, mutational screening was performed by MLPA, Sanger and next generation sequencing. Mutations were detected in FANCA ( 7 of 10), FANCG (1 of 10), and FANCD2 (1 of 10), while no detectable pathogenic variants were found in one individual (Table 3). Among the pathogenic variants, three (FANCA c.2851C $>$ T, FANCA, c.2738A > C, FANCG c.1182_1192delinsC) have been described earlier and six (FANCA del exon 3-5, FANCA c. 427-3C > G, FANCA c.3586G > T, FANCA del exon 1-2, FANCA c. $1229 \mathrm{G}>$ A, FANCD2 c. $1766+40 \mathrm{~T}>\mathrm{G}$ ) were novel. Proper segregation for patients with novel mutations was confirmed for the cases (HUSCS-FA01 and HUSCS-FA09.a) from which DNA from the parents was available.

Two splice site variants were further analyzed. A patient (HUSCS-FA02) had a predicted aberrant splicing mutation in intron 4 (Supplementary Fig. 1a). The splice site mutation was confirmed by amplification of the patient's cDNA, which gave some residual full-length splice product $(480 \mathrm{bp}$ ) and a $100 \mathrm{bp}$ shorter amplicon (Supplementary Fig. 1b). gDNA from another patient (HUSCS-FA09.a) had a de novo nucleotide substitution in intron 19 of FANCD2 gene identified by next generation sequencing (Supplementary Fig. 1c) and validated using cDNA by Sanger sequencing (Table 3; Supplementary Fig. 1d). This mutation was predicted to create a unique second splice site, which would extend exon 19 by adding $39 \mathrm{bp}$ and this extension contained an in-frame stop codon (TGA).

\section{Characterization of BM-MSCs}

All BM-MSCs were positive for most mesenchymal markers (CD29, CD44, CD73, CD90, CD105, CD140b, CD146, CD166, HLA-ABC), whereas they had low or no expression of others $\left(\mathrm{CD} 106^{\text {low/- }}, \mathrm{CD} 200^{\text {low }}, \mathrm{CD} 271^{-}\right)$. Additionally, all BM-MSCs were negative for endothelial markers CD31 and CD144, hematopoietic markers CD34, CD14, CD45, and HLA-DR as well as the general stem cell marker CD133 (Fig. 1a; see Supplementary Fig. 2 for raw plots). Cell surface marker expression was similar between BMMSCs of FA patients and healthy donors $(P>0.05$; Fig. 1a). However, CD29 levels of FA BM-MSCs were significantly higher compared with donor cells $(P<0.05$; Fig. 1a). There were no differences in adipogenic and osteogenic potency between FA and donor BM-MSCs (Supplementary Fig. 3). Expression of adipogenic gene $L P L(P>0.05$; Fig. 1b) and osteogenic gene $A L P L(P>0.05$; Fig. 1c) was similar between two groups. Proliferative potency of FA patient and donor BM-MSCs was determined from cell passage P3 to $\mathrm{P} 7$ by calculating cumulative population doublings (cPD) at each passage. The cPD of donor $(10.93 \pm 2.73)$ and FANCAdeficient patient $(10.30 \pm 0.16)$ BM-MSCs was similar from P3 to P7 (Fig. 1d). Proliferation of FANCG-deficient patient cells was arrested at P6 but cPD of the patient $(=8.86)$ was similar to donors from P3 to P6. Patients with a FANCD2 mutation had a lower proliferative capacity compared to other samples. BM-MSCs from one of the FANCD2-deficient patients ceased to grow at $\mathrm{P} 4(\mathrm{cPD}=1.33)$ and from another patient cPD was 7.90 at P7 (Fig. 1d). Senescence of FA patients and donor BM-MSCs was detected at P3 and $\mathrm{P} 6$ by positive $\beta$-gal staining (Fig. 1e). At early passage (P3), both patients with unknown and FANCA mutations had lower SA- $\beta$-gal activity compared to donors. P6 BM-MSCs from patients with unknown and FANCA mutations and donors had higher SA- $\beta$-gal activity and displayed larger cell morphology compared to their P3 cultures. At P3, FANCD2-deficient patient had a slightly higher SA- $\beta$-gal activity compared to other groups and displayed enlarged cell morphology as well (Fig. 1e). The ROS level of BM-MSCs from FA patients and donors was compared using a general oxidative stress indicator (Fig. 1f). Patients cells had relatively higher ROS production compared to donor cells $(P>0.05$; Fig. 1f). Mean FI intensity of CMH2DCFDA was $150,513( \pm 34,648)$ in FA-A patients and $135,111( \pm 12,665)$ in FA-D2 patients, compared to 112,002 $( \pm 15,981)$ in donors.

Prior to DEB treatment, the majority of BM-MSCs were in the dip G1 phase of the cell cycle (Supplementary Fig. 4). The fold change in donor cell numbers before 

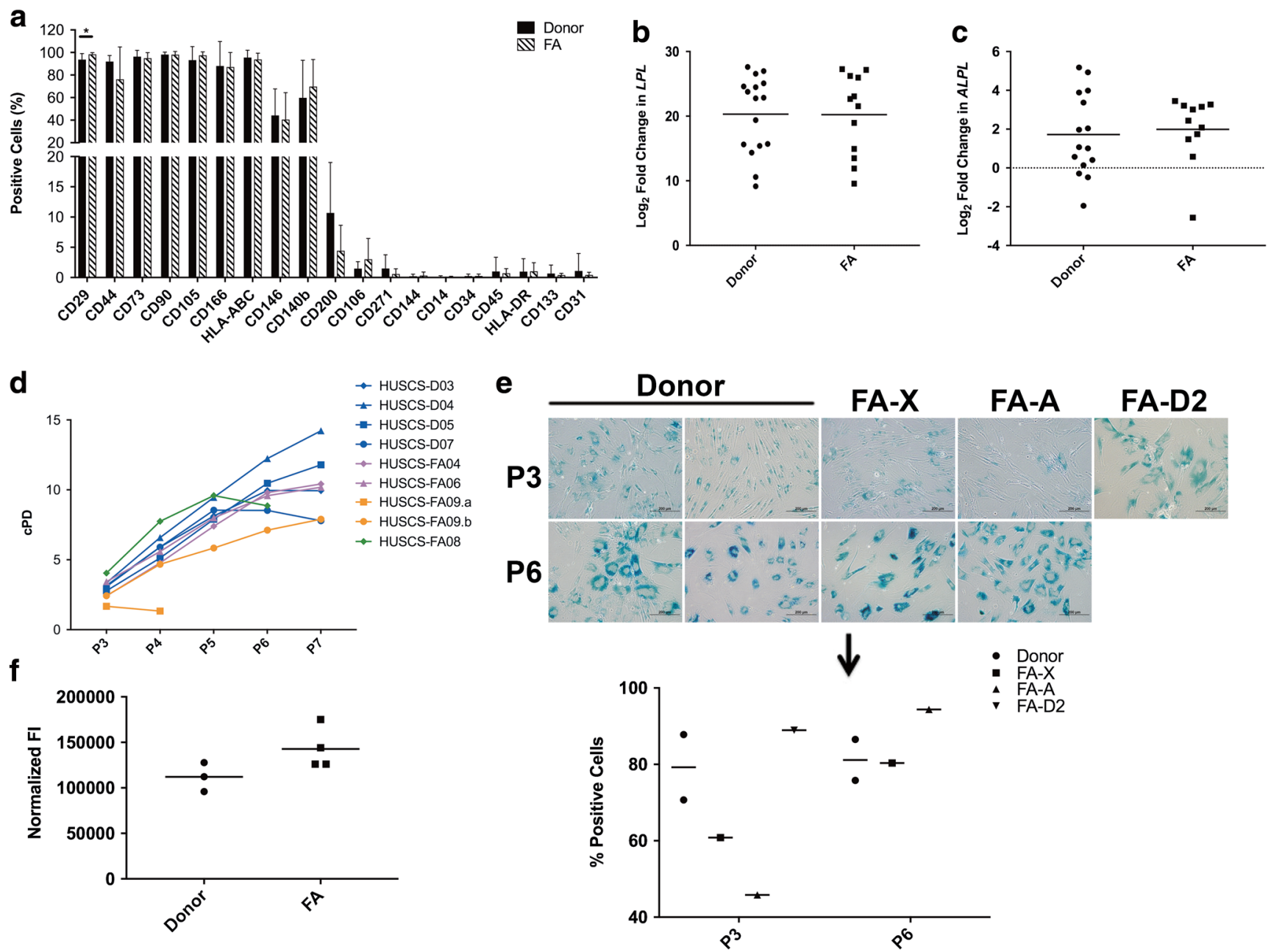

Fig. 1 Characterization of FA and donor BM-MSCs. (a) Immunophenotypes of patient and donor cells. (b) Fold change of adiposespecific gene, $L P L$ in cultures containing differentiated adipocytes of donor $(n=16)$ and patients $(n=12)$ compared to undifferentiated cells. (c) Fold change of bone-specific gene, $A L P L$, in cultures containing differentiated osteocytes of donor $(n=15)$ and FA patients $(n=11)$ compared to undifferentiated cells. (d) Proliferative potency

and after DEB treatment for each cell cycle phase was negligible (Fig. 2 and Supplementary Table 3). However, cell cycle behavior of FA-derived BM-MSCs differed after treatment (Supplementary Fig. 4 and Supplementary Table 3). Following DEB treatment, there was a significant decrease in patient cell numbers $(\mathrm{fc}=-29.83 \pm 11.67)$ compared to donors $(\mathrm{fc}=-5.13 \pm 5.69)$ in dip G1 phase $(P<0.05$; Fig. 2). However, there was a significant increase $(P<0.05)$ in FA BM-MSCs $(\mathrm{fc}=36.18 \pm 13.40)$ within the dip $\mathrm{G} 2$ phase compared to donor cells (fc $=0.29 \pm 0.24$; Fig. 2). These results suggest abnormal cell cycle regulation of patient BM-MSCs following DEB treatment. One of the FA-A patients (HUSCS-FA06) was excluded from the analysis due to low number $(<5000)$ of modeled events.

of FA cells $(n=5)$ was determined between P3 to P7 and compared with donors $(n=4)$ by calculating cumulative population doubling (cPD) at each passage. (e) Senescence of FA patient BM-MSCs $(n=3)$ was evaluated at $\mathrm{P} 3$ and $\mathrm{P} 6$ by SA- $\beta$-gal activity and compared with donor BM-MSCs $(n=2)$. Patients with unknown FA mutations were depicted as FA-X. (f) ROS production of BM-MSCs from FA patients $(n=4)$ and donors $(n=3)$ was assessed

\section{TGF- $\beta$ Expression and Secretion Level of FA and Donor BM-MSCs}

TGF- $\beta 1$ gene expression level of both $\mathrm{P} 3$ donor $(n=10 ; 11.2 \pm 6.1$ years of age, Table 2$)$ and FA $(n=7$; $12.0 \pm 3.6$ years of age, Table 2) patient BM-MSCs was similar $(P>0.05$; Fig. 3a). DEB treatment had no effect on the expression of donor $(n=3 ; 9.3 \pm 8.7$ years of age, Table 2) and FA ( $n=6 ; 8.8 \pm 3.9$ years of age, Table 2$)$ BM-MSCs (Fig. 3b). However, one donor (HUSCS-D11) and one FANCA-deficient (HUSCS-FA04) BM-MSC had a notable decrease in TGF- $\beta 1$ expression following DEB treatment (Fig. 3b). TGF- $\beta 1$ secretion levels of BM-MSCs varied widely among the individuals, both in donors and patients (Supplementary Table 4). Overall TGF- $\beta 2$ and 


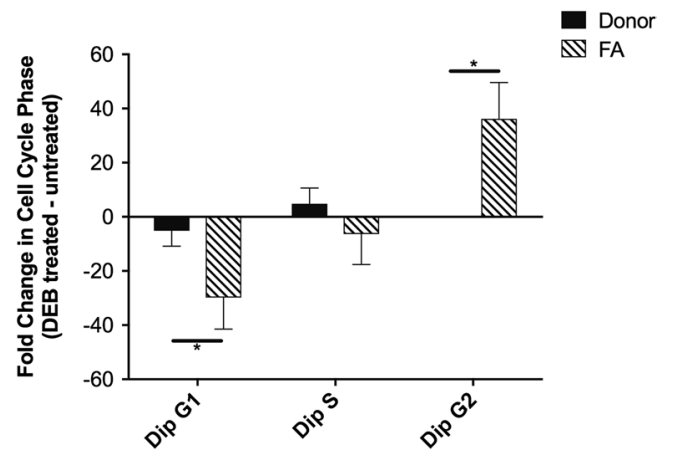

Fig. 2 The effect of DEB treatment on cell cycle of FA and donor BM-MSCs. Following DEB treatment, there was a significant decrease in FA cells within dip G1 phase compared to donors $(P<0.05)$. Within dip $\mathrm{G} 2$ phase, there was a significant increase in FA BM-MSCs compared to donors $(P<0.05)$. The results are presented as fold change in the percentage of positive cells in each cell cycle phase (\% of DEB treated BM-MSCs - \% of control BM-MSCs). $*$, depicts statistically significant difference $(P<0.05)$
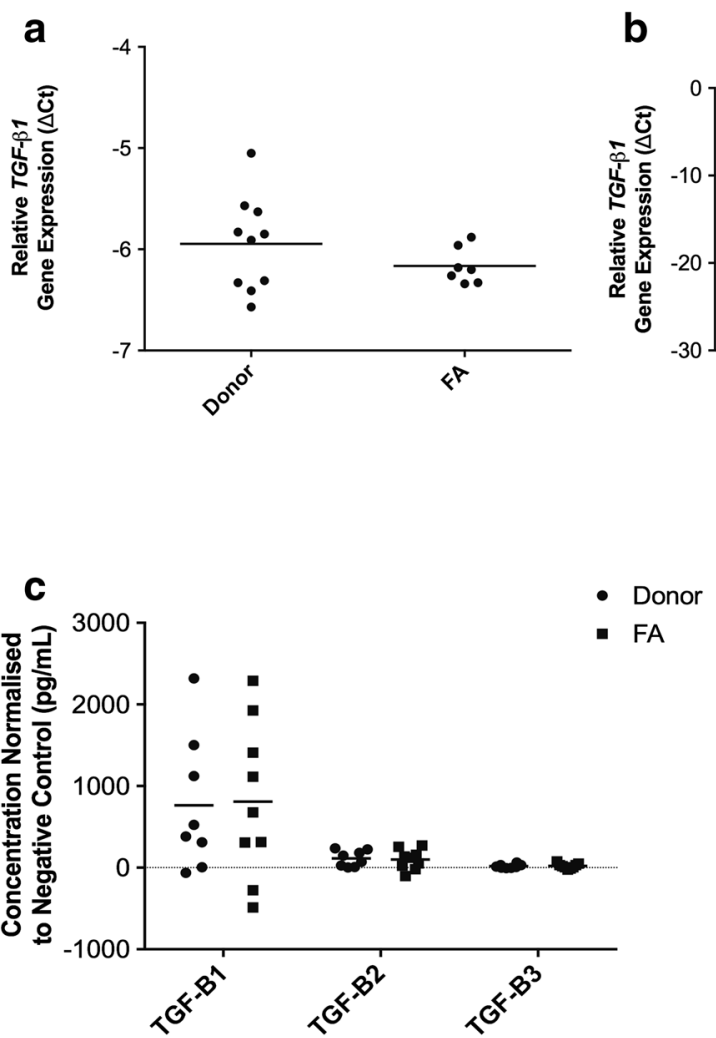

Fig. 3 TGF- $\beta$ levels of FA and donor BM-MSCs. (a) and (b) show $T G F-\beta 1$ expression level normalized to $A C T B . \Delta \mathrm{Ct}=-25$ indicates lack of expression. (a) FA patients $(n=7)$ had similar TGF- $\beta 1$ gene expression $(P>0.05)$ compared to donors $(n=10)$. (b) Following DEB treatment, the expression TGF- $\beta 1$ in BM-MSCs was slightly downregulated. (c) TGF- $\beta$ secretion levels that were normalized to growth medium. TGF- $\beta 1$ secretion levels of BM-MSCs varied a lot

b

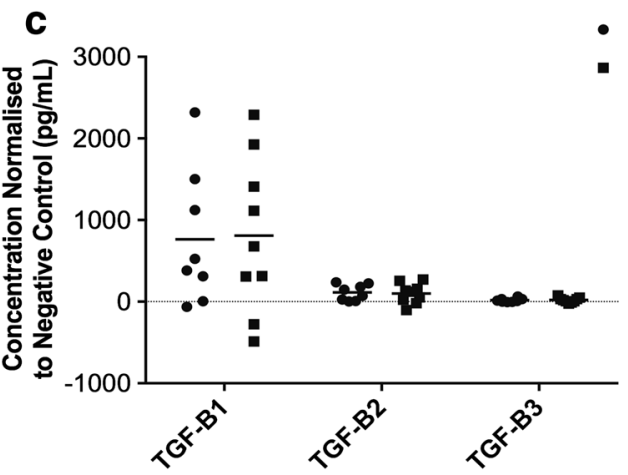

TGF- $\beta 3$ secretion was low compared to TGF- $\beta 1$ levels (Supplementary Table 4$)$. TGF- $\beta 1$, TGF- $\beta 2$, TGF- $\beta 3$ secretion by FA BM-MSCs $(808.32 \pm 953.30,99.58 \pm 123.20$ and $20.28 \pm 31.22 \mathrm{pg} / \mathrm{mL}$, respectively) was similar $(P>0.05)$ to donor cells $(763.05 \pm 824.47,112.70 \pm 97.42$ and $17.44 \pm 23.48 \mathrm{pg} / \mathrm{mL}$, respectively). In the supernatants of the BM-MSCs of FANCD2-deficient patients, however, TGF- $\beta 1 / 2 / 3$ levels were not detected (Fig. 3c).

\section{Effect of rTGF- $\beta 1$ Induction on the Proliferative Potential of FA and Donor BM-MSCs}

An impedance-based real-time assay was used to assess the proliferative potential of BM-MSCs from FA patients and donors. Following the initial addition of rTGF- $\beta 1$, the cell index of all samples increased depending on the concentration of recombinant protein (Fig. 4a-b). At later time points, proliferation of BM-MSCs treated with $5 \mathrm{ng} / \mathrm{ml}$ rTGF- $\beta 1$ decreased (Fig. 4a). Doubling time of BM-MSCs was also calculated following the initial induction (Fig. 4a-b). Doubling time of patient and donor BM-MSCs grown in DMF10 or medium supplemented

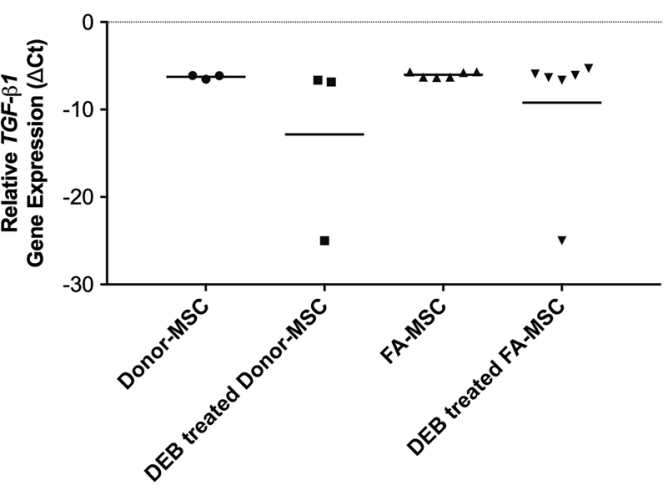

between the individuals both in donors $(n=8)$ and patients $(n=9)$. Some BM-MSCs had high, some had medium and some had low TGF- $\beta 1$ secretion. TGF- $\beta 2$ and TGF- $\beta 3$ were very low in all samples. However, TGF- $\beta 1 / \beta 2 / \beta 3$ production by donor BM-MSCs was similar to patients $(P>0.05)$. FANCD2-deficient BM-MSCs did not secrete TGF- $\beta$ isoforms at all 
a

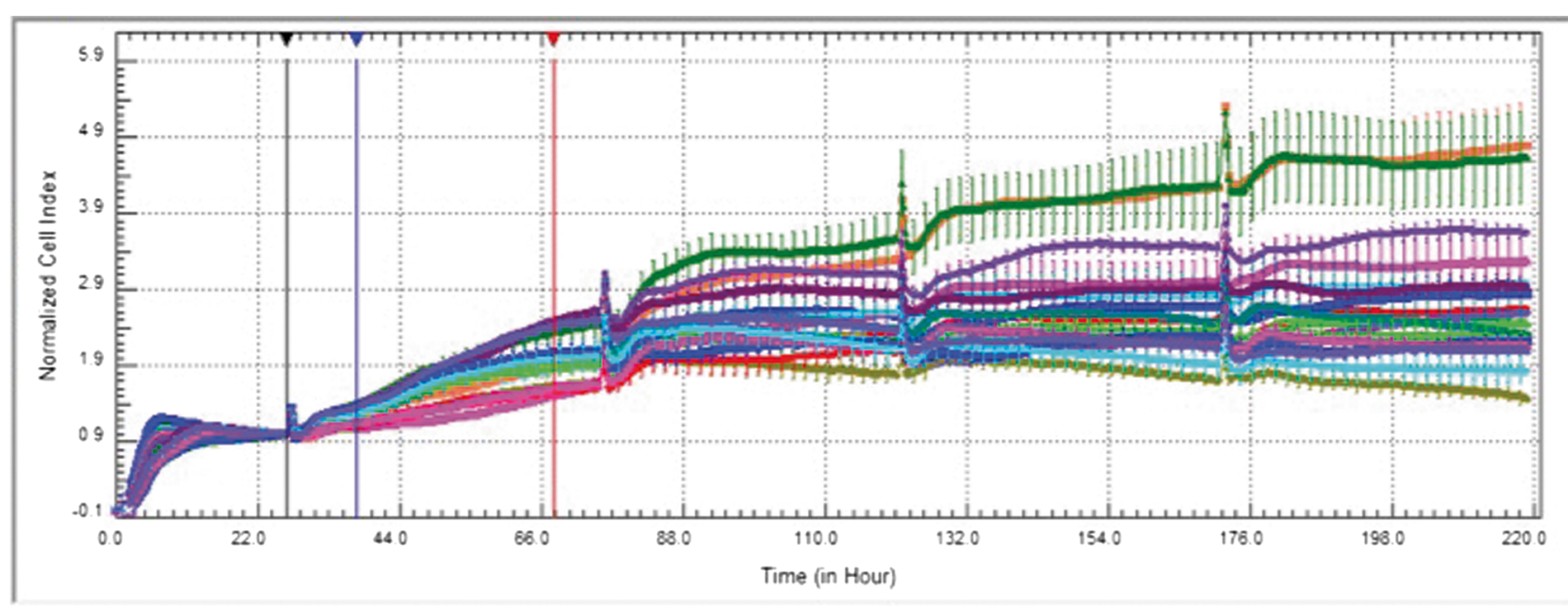

b

BM-MSC Basal Medium

$0.1 \mathrm{ng} / \mathrm{mL}$ rTGF- $\beta 1$

$5 \mathrm{ng} / \mathrm{mL}$ rTGF- $\beta 1$

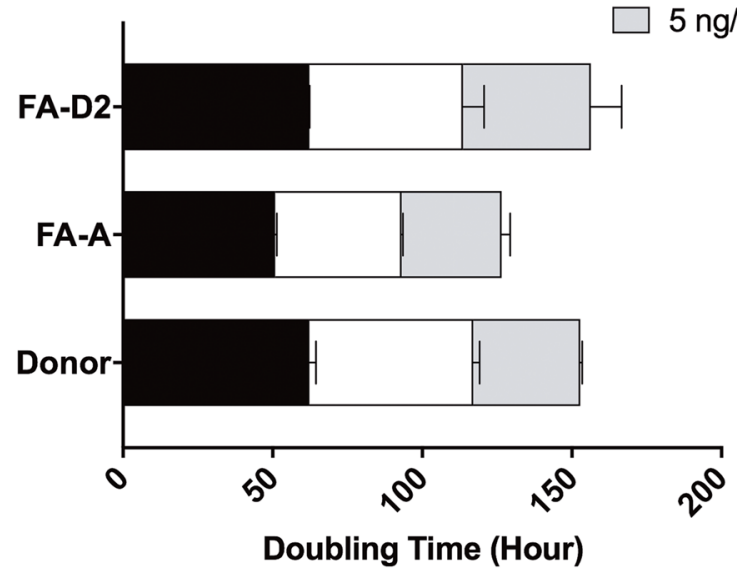

Fig. 4 Effect of rTGF- $\beta 1$ induction on the proliferation of FA-A $(n=2)$, FA-D2 $(n=2)$ and donor $(n=2)$ BM-MSCs was determined. (a) Line graph showing change in normalized cell index over time.

(b) Doubling times of FA-A $(n=2)$, FA-D2 $(n=2)$ and donor $(n=2)$ BM-MSCs in basal medium (DMF10) and in $0.1 \mathrm{ng} / \mathrm{ml}$ and $5 \mathrm{ng} / \mathrm{ml}$ rTGF- $\beta 1$ containing medium

with 0.1 or $5 \mathrm{ng} / \mathrm{mL}$ rTGF- $\beta 1$ was similar $(P>0.05)$. However, the doubling time of FA-D2 BM-MSCs cultured in DMF10 medium $(62.28 \pm 0.04 \mathrm{~h})$ was slightly higher than cells derived from FA-A patients $(50.87 \pm 0.47 \mathrm{~h})$ but similar to donors $(62.27 \pm 2.18 \mathrm{~h}$; Fig. 4b). Additionally, fold change in doubling time of FANCD2-deficient BM-MSCs induced with either 0.1 or $5 \mathrm{ng} / \mathrm{mL}$ recombinant protein $(0.82 \pm 0.11$ and $0.69 \pm 0.17$, respectively) was similar with FANCA-deficient BM-MSCs $(0.83 \pm 0.02$ and $0.66 \pm 0.06$, respectively $)$ or donor BM-MSCs $(0.88 \pm 0.00$ and $0.57 \pm 0.03$, respectively; Table 4$)$.

\section{Discussion}

The role of the niche on HSC behavior and regulation has begun to be elucidated decades ago, but still few is known about the identity and behavior of the niche component stromal progenitors. These cells are critical, not only because of their supportive role for HSCs, but also because they can signal to HSCs or epithelial cells in other tissues and contribute to changes in cellular identity. Defining mesenchymal progenitors in the bone marrow niche in genome unstable disease states may help to understand not only their tissue support, but also the early signals in leukemia or cancer development. In this study, we characterized the BM-MSCs from FA individuals and donors to determine the effect of FA on these important BM-niche components. FA is a rare genetic disorder that occurs 1 in 160,000 people worldwide [35]. First, molecular classification of nine cases out of ten independent subjects was conducted by identifying pathogenic variants. Molecular classification of two cases could not be performed due to lack of coverage or the involvement of currently unknown FA gene. The classified individuals were affected by 
Table 4 Fold change in doubling time of BM-MSCs derived from FA-A, FA-D2 and donors was determined after initial addition of rTGF- $\beta 1$ protein between 37:46:27 and 68:17:04 h

\begin{tabular}{llcc}
\hline & \multicolumn{2}{l}{ Fold Change in Doubling Time by rTGF- $\beta 1^{* *}$} \\
\cline { 2 - 4 } & MSC Basal Medium* & $0.1 \mathrm{ng} / \mathrm{mL}$ rTGF- $\beta 1$ & $5 \mathrm{ng} / \mathrm{mL}$ rTGF- $\beta 1$ \\
\hline Donor BM-MSC & $1.00 \pm 0.00$ & $0.88 \pm 0.00$ & $0.57 \pm 0.03$ \\
FA-A BM-MSC & $1.00 \pm 0.00$ & $0.83 \pm 0.02$ & $0.66 \pm 0.06$ \\
FA-D2 BM-MSC & $1.00 \pm 0.00$ & $0.82 \pm 0.11$ & $0.69 \pm 0.17$ \\
\hline
\end{tabular}

*Depicts DMF10 medium;

**Fold change was calculated by dividing doubling time of rTGF- $\beta 1$ treated BM-MSC to the population doubling of corresponding BM-MSC in basal medium homozygous mutations in FANCA, FANCG and FANCD2, and of six were novel mutations (five in FANCA and one in FANCD2). Two patients, whose DEB-tests were negative, were found to belong to the FA-A complementation group, and results may be attributed to mosaicism. The two patients carrying FANCD2 mutations displayed typical FA phenotypes, including microcephaly, hyper/hypopigmentation, growth retardation and microphthalmia. The FA-D2 complementation group has been demonstrated to possess a relatively severe phenotypic outcome in both humans [36, 37] and their corresponding animal models [38, 39]. Kalb and colleagues (2007) reported that patients with mutations in FANCD2 have early onset and more rapid progression of hematological manifestations, and usually multiple congenital anomalies [36]. Additionally, the identified FANCD2 mutations in humans are only hypomorphic, which suggests biallelic null mutations are lethal [36], thus confirming FANCD2-defiency as severe.

In the present study, BM-MSCs derived from FA patients and donors were thoroughly characterized. A broad range of markers was used for immunophenotyping the BM-MSCs. Cells of both groups displayed similar immunophenotypes, as previously shown $[15,16]$. However, CD29 ( $\beta 1$-integrin) level of FA patients was significantly higher than donor cells. CD29 has been shown to be important for MSC migration [40] suggesting that FA patient cells may have impaired migration. The CD200 (OX-2) levels were slightly lower in FA MSCs compared to donors. Several tissues are positive for CD200 and only cells from myeloid-lineage express its receptor (CD200R). Percentage of CD200 positive cells can vary from high to low in BM-MSC population and the CD200-CD200R interaction causes down regulation of immune cells [41]. Our study demonstrated that CD200-positive BM-MSCs were present at low levels in both donor and FA patient MSCs with insignificant difference $(P=0.064)$. The CD271 levels were also expressed at low levels, which was in line with the previously observed downregulation of CD271 upon MSC culture [42, 43].

It has been suggested that osteoblast dysfunction can support myelodysplastic syndromes and acute myeloid leukemia [44]. A recent report provides evidence that numerical impairment of osteoblastic niche resides after bone marrow transplantation [12]. Therefore, we investigated whether there was an abnormality in differentiation of FA BM-MSC to osteoblasts. The BM-MSCs from different individuals varied widely in differentiation capacity and in general had a higher adipogenic differentiation than osteogenic differentiation potential, but donor and FA patient differentiation capacity did not significantly differ from each other. An inverse relationship between osteogenic and adipogenic differentiation is known and some steady state signaling pathways preferentially poise MSCs to be more potent for adipogenic lineage or osteogenic differentiation [45]. Even though the present differentiation data are in line with a previous study by Mantelli et al. (2015) [16], it contradicts another study showing defective osteoblast differentiation of human FA MSCs [46].

After DEB treatment, we found that the number of FA patient BM-MSCs in dip G2 phase increased, while it decreased in dip G1 phase compared to donors, confirming previously published data [16]. BM-MSCs are shown to be prone to spontaneous chromosomal breaks at steady state conditions, while DEB treatment does not upregulate the number of these breaks [16]. The disability of FA-derived BM-MSCs to proliferate and to repair spontaneous chromosomal breaks might trigger long-term BMF.

BM-MSCs derived from FANCA- or $F A N C G$-deficient patients showed similar ex vivo proliferative capacity as donor cells from $\mathrm{P} 3$ to $\mathrm{P} 7$. In concordance with our results, Mantelli et al. (2015) report that BM-MSCs from FANCA patients and donors have similar cPD at early passages (from P1 to P5) [16]. However, in the present study FANCD2deficient cell displayed slightly lower proliferative capacity compared to normal cells as assessed in terms of population doubling. Similarly, Yamamoto et al. (2005) reported that FANCD2-deficient cells have a slower growth rate, compared to wild types [47]. Compared with donors, BM-MSCs derived from a patient with a FANCA mutation had similar $\beta$-gal positivity at $\mathrm{P} 6$, while cell displaying FANCD2 mutation had higher activity at $\mathrm{P} 3$ indicating premature aging of these cells. Furthermore, we showed that FANCA-deficient and donor BM-MSCs could be expanded until P8-P10 and P7-P11, respectively (data not shown) while FANCG- (P6) or FANCD2- (P4-P7) deficient cells underwent growth arrest 
earlier. Mantelli et al. (2015) reported that donor (P13-P21) and FANCA-deficient (P4-P17) BM-MSCs have higher in-vitro expansion capacities than cells used in this study, although they also found that FA cells undergo replicative senescence earlier than donors [16].

TGF- $\beta$ is known to inhibit HSC proliferation as reviewed by Blank et al. (2008) [1]. Recently, hyperactive TGF- $\beta$ signaling in FA patient HSCs has been suggested to cause BMF [17]. Though TGF- $\beta$ is important for tumor suppression it can also promote tumor growth by remodeling the niche [4]. Mice knockout experiments showed the need for $T G F-\beta$ for development of myelofibrosis [48]. TGF- $\beta$ also provides signal for HSC dormancy in the BM niche [18]. However, mitotic progression in murine BM-MSCs is promoted by TGF- $\beta$ signaling [49]. Here, we assessed TGF- $\beta$ production by FA BM-MSCs at mRNA and protein level. $T G F-\beta 1$ expression of both donor and FA patient BMMSCs was similar. Additionally, active TGF- $\beta 1$, TGF- $\beta 2$ and TGF- $\beta 3$ secretion by FA BM-MSCs was similar to donors, while FANCD2-deficient patients did not secrete TGF- $\beta$ s at all. Secretion of active TGF- $\beta$ s is known to autoregulate TGF- $\beta$ signaling. Together with Letterio et al. (1996) showing enhanced myelopoiesis and autoimmunity in $T G F-\beta 1$ null mice [50], our data suggests that FANCD2-deficient patients might be more prone to BMF and myelodysplasia. On the other hand, TGF- $\beta$ changes the suppressive behavior of BM-MSCs to an immune activating state [51]. Increased TGF- $\beta$ secretion by FA HSCs may create an autoimmune-like bone marrow and lead BM-MSCs to respond by downregulating TGF- $\beta$. Accordingly, Rizzo et al. (1999) indicate that bone marrow stroma from aplastic anemia patients has significantly lower TGF- $\beta 1$ production compared with donors and the reduction is correlated with the severity of the disease [52]. Similar doubling time of FA-D2 BM-MSCs compared to donor BM-MSCs, indicated that decreased proliferative capacity of FANCD2-deficient BM-MSCs was not due to lack of TGF- $\beta 1$ production. Additionally, when FA-D2, FA-A and donor BM-MSCs were treated with rTGF- $\beta 1$, there was no major difference in cell proliferation between patients and donors or FA-A and FA-D2. However, BM-MSC proliferation was temporarily decreased in response to treatment with a high dose of rTGF- $\beta 1$. In agreement with the results of a study showing an increased senescence in mouse BMMSCs with TGF- $\beta$ induction [53], our results suggest that premature (i.e. stress related) senescence in FA BMMSCs may be due to paracrine effects. Further investigation of BM-MSCs for epigenetic changes by TGF- $\beta$ may enlighten this conclusion. The same study demonstrated that TGF- $\beta$ increased mitochondrial ROS production [53]. We showed that ROS production was slightly higher in FA BM-MSCs compared to donors, in concordance with previously published data [54]. Therefore, downregulation of TGF- $\beta$ in FA-D2 BM-MSCs may be a protective response to damaging effects of ROS. A study showing reduction of TGF- $\beta$ signaling by oxidative exposure [55] and another recent study establishing the protective role of FANCD2 from ferroptosis [56] strengthens this conclusion. In light of the TGF- $\beta$ requirement for the development of myelofibrosis [48], it can be speculated that down-regulation of TGF- $\beta$ in BM-MSCs may even delay myelofibrosis of FA-D2 bone marrow.

In conclusion, here we report six novel mutations, five in FANCA and one in FANCD2. TGF- $\beta$ secretion does not significantly change between donor BM-MSCs and FA BM-MSCs, apart from FANCD2-deficient cells. Absence of TGF- $\beta$ secretion may be a cause of early onset of senescence, but not growth inhibition of FANCD2-deficient BM-MSCs. It can also be a consequence of protective response to either FA HSCs secreting TGF- $\beta$ or probable increased ROS production in FA BM-MSCs. Further studies involving FA complementation groups with severe phenotype are needed to substantiate these hypotheses. Given the critical and complex role of BM-MSC in HSC fate, these data complement previous mouse and patient studies and may be of value to understand bone marrow dysfunction in Fanconi anemia in humans.

Acknowledgements The authors thank Prof. Emin Kansu for his input and the critical review of the manuscript. The authors also acknowledge the deceased Prof. Johan de Winter for his invaluable guidance and collaboration between Hacettepe University and VU Medical Center for FA mutation investigations.

Funding This study was funded by The Scientific and Technological Research Council of Turkey (TUBITAK 1001 project 110S021 in conjunction with EU COST Action BM0805 designated as 'HOX and TALE transcription factors in Development and Disease' and TUBITAK 1001 Project No: 214Z033).

\section{Compliance with Ethical Standards}

Conflict of interest The authors declare that they have no conflict of interest.

\section{References}

1. Blank, U., Karlsson, G., \& Karlsson, S. (2008). Signaling pathways governing stem-cell fate. Blood, 111(2), 492-503.

2. Beerman, I., Luis, T. C., Singbrant, S., Lo Celso, C., \& MendezFerrer, S. (2017). The evolving view of the hematopoietic stem cell niche. Experimetal Hematology, 50, 22-26.

3. Pittenger, M. F., Mackay, A. M., Beck, S. C., Jaiswal, R. K., Douglas, R., Mosca, J. D., et al. (1999). Multilineage potential of adult human mesenchymal stem cells. Science, 284(5411), 143-147.

4. Schepers, K., Pietras, E. M., Reynaud, D., Flach, J., Binnewies, M., Garg, T., et al. (2013). Myeloproliferative neoplasia remodels 
the endosteal bone marrow niche into a self-reinforcing leukemic niche. Cell Stem Cell, 13(3), 285-299.

5. Ceccaldi, R., Parmar, K., Mouly, E., Delord, M., Kim, J. M., Regairaz, M., et al. (2012). Bone marrow failure in Fanconi anemia is triggered by an exacerbated p53/p21 DNA damage response that impairs hematopoietic stem and progenitor cells. Cell Stem Cell, 11(1), 36-49.

6. Kutler, D. I., Singh, B., Satagopan, J., Batish, S. D., Berwick, M., Giampietro, P. F., et al. (2003). A 20-year perspective on the International Fanconi Anemia Registry (IFAR). Blood, 101(4), 1249-1256.

7. Mamrak, N. E., Shimamura, A., \& Howlett, N. G. (2017). Recent discoveries in the molecular pathogenesis of the inherited bone marrow failure syndrome Fanconi anemia. Blood Reviews, 31(3), 93-99.

8. Knies, K., Inano, S., Ramirez, M. J., Ishiai, M., Surralles, J., Takata, M., \& Schindler, D. (2017). Biallelic mutations in the ubiquitin ligase RFWD3 causes Fanconi anemia. The Journal of Clinical Investigation, 127(8), 3013-3027.

9. Ceccaldi, R., Sarangi, P., \& D’Andrea, A. D. (2016). The Fanconi anemia pathway: new players and new functions. Nature Reviews. Molecular Cell Biology, 17(6), 337-349.

10. Wegman-Ostrosky, T., \& Savage, S. A. (2017). The genomics of inherited bone marrow failure: from mechanism to the clinic. British Journal of Haematology, 177(4), 526-542.

11. Kee, Y., \& D'Andrea, A. D. (2012). Molecular pathogenesis and clinical management of Fanconi anemia. The Journal of Clinical Investigation, 122(11), 3799-3806.

12. Wu, L., Mo, W., Zhang, Y., Zhou, M., Li, Y., Zhou, R., et al. (2017). Vascular and perivascular niches, but not the osteoblastic niche, are numerically restored following allogeneic hematopoietic stem cell transplantation in patients with aplastic anemia. International Journal of Hematology, 106(1), 71-81.

13. Anur, P., Friedman, D. N., Sklar, C., Oeffinger, K., Castiel, M., Kearney, J., et al. (2016). Late effects in patients with Fanconi anemia following allogeneic hematopoietic stem cell transplantation from alternative donors. Bone Marrow Transplantation, 51(7), 938-944.

14. Rosenberg, P. S., Socie, G., Alter, B. P., \& Gluckman, E. (2005). Risk of head and neck squamous cell cancer and death in patients with Fanconi anemia who did and did not receive transplants. Blood, 105(1), 67-73.

15. Lecourt, S., Vanneaux, V., Leblanc, T., Leroux, G., Ternaux, B., Benbunan, M., et al. (2010). Bone marrow microenvironment in fanconi anemia: a prospective functional study in a cohort of fanconi anemia patients. Stem Cells and Development, 19(2), 203-208

16. Mantelli, M., Avanzini, M. A., Rosti, V., Ingo, D. M., Conforti, A., Novara, F., et al. (2015). Comprehensive characterization of mesenchymal stromal cells from patients with Fanconi anaemia. British Journal of Haematology, 170(6), 826-836.

17. Zhang, H., Kozono, D. E., O'Connor, K. W., Vidal-Cardenas, S., Rousseau, A., Hamilton, A., et al. (2016). TGF-beta Inhibition Rescues Hematopoietic Stem Cell Defects and Bone Marrow Failure in Fanconi Anemia. Cell Stem Cell, 18(5), 668-681.

18. Blank, U., \& Karlsson, S. (2015). TGF-beta signaling in the control of hematopoietic stem cells. Blood, 125(23), 3542-3550.

19. Yahata, T., Ibrahim, A. A., Muguruma, Y., Eren, M., Shaffer, A. M., Watanabe, N., et al. (2017). TGF- $\beta$-induced intracellular PAI-1 is responsible for retaining hematopoietic stem cells in the niche. Blood. http://dx.doi.org/10.1182/blood-2017-02-767384.

20. Ruscetti, F. W., Akel, S., \& Bartelmez, S. H. (2005). Autocrine transforming growth factor-beta regulation of hematopoiesis: many outcomes that depend on the context. Oncogene, 24(37), $5751-5763$.
21. Epperly, M. W., Rhieu, B. H., Franicola, D., Dixon, T., Cao, S., Zhang, X., et al. (2017). Induction of TGF-beta by irradiation or chemotherapy in Fanconi Anemia (FA) mouse bone marrow is modulated by small molecule radiation mitigators JP4-039 and MMS350. In Vivo, 31(2), pp. 159-168.

22. Gille, J. J., Floor, K., Kerkhoven, L., Ameziane, N., Joenje, H., \& de Winter, J. P. (2012). Diagnosis of Fanconi Anemia: mutation analysis by multiplex ligation-dependent probe amplification and PCR-based sanger sequencing. Anemia, 2012:603253.

23. Schouten, J. P., McElgunn, C. J., Waaijer, R., Zwijnenburg, D., Diepvens, F., \& Pals, G. (2002). Relative quantification of 40 nucleic acid sequences by multiplex ligation-dependent probe amplification. Nucleic Acids Research, 30(12), e57.

24. Naipal, K. A., Verkaik, N. S., Ameziane, N., van Deurzen, C. H., Ter Brugge, P., Meijers, M., et al. (2014). Functional ex vivo assay to select homologous recombination-deficient breast tumors for PARP inhibitor treatment. Clinical Cancer Research, 20(18), 4816-4826.

25. Levran, O., Diotti, R., Pujara, K., Batish, S. D., Hanenberg, H., \& Auerbach, A. D. (2005). Spectrum of sequence variations in the FANCA gene: an International Fanconi Anemia Registry (IFAR) study. Human Mutation, 25(2), 142-149.

26. Demuth, I., Wlodarski, M., Tipping, A. J., Morgan, N. V., de Winter, J. P., Thiel, M., et al. (2000). Spectrum of mutations in the Fanconi anaemia group G gene, FANCG/XRCC9. European Journal of Human Genetics, 8(11), 861-868.

27. Cagnan, I., Kaya, A., Cetinkaya, F., Gunel Ozcan, D., G (2017). Stably expressed reference genes during differentiation of bone marrow-derived mesenchymal stromal cells. Turkish Journal of Biology, 41, 88-97.

28. Zuk, P. A., Zhu, M., Mizuno, H., Huang, J., Futrell, J. W., Katz, A. J., et al. (2001). Multilineage cells from human adipose tissue: implications for cell-based therapies. Tissue Engineering, 7(2), 211-228.

29. D'Andrea, A. D., \& Grompe, M. (2003). The Fanconi anemia/ BRCA pathway. Nature Review., Cancer, 3(1), 23-34.

30. Meetei, A. R., Levitus, M., Xue, Y., Medhurst, A. L., Zwaan, M., Ling, C., et al. (2004). X-linked inheritance of Fanconi anemia complementation group B. Nature Genetics, 36(11), 1219-1224.

31. Auerbach, A. D. (2015). Diagnosis of Fanconi anemia by diepoxybutane analysis. Current Protocols in Human Genetics. https://doi.org/10.1002/0471142905.hg0807s85.

32. Gomez, K. A., \& Gomez, A. A. (1984). Statistical procedures for agricultural research. New York, NY: John Wiley \& Sons, Inc.

33. Rieu, I., \& Powers, S. J. (2009). Real-time quantitative RTPCR: design, calculations, and statistics. The Plant Cell, 21(4), 1031-1033.

34. Livak, K. J., \& Schmittgen, T. D. (2001). Analysis of relative gene expression data using real-time quantitative PCR and the 2(-Delta Delta C(T)) Method. Methods, 25(4), 402-408.

35. Crawford, D., \& Dearmun, A. (2017). Fanconi anemia. Nursing Children and Young People, 29(1), 17.

36. Kalb, R., Neveling, K., Hoehn, H., Kalb, R., Schneider, H., Linka, Y., Batish, S. D., et al. (2007). Hypomorphic mutations in the gene encoding a key Fanconi anemia protein, FANCD2, sustain a significant group of FA-D2 patients with severe phenotype. American Journal of Human Genetics, 80(5), 895-910.

37. Taniguchi, T., Garcia-Higuera, I., Andreassen, P. R., Gregory, R. C., Grompe, M., \& D'Andrea, A. D. (2002). S-phase-specific interaction of the Fanconi anemia protein, FANCD2, with BRCA1 and RAD51. Blood, 100(7), 2414-2420.

38. Liu, T. X., Howlett, N. G., Deng, M., Langenau, D. M., Hsu, K., Rhodes, J., et al. (2003). Knockdown of zebrafish Fancd 2 causes developmental abnormalities via p53-dependent apoptosis. Developmental Cell, 5(6), 903-914. 
39. Parmar, K., D’Andrea, A., \& Niedernhofer, L. J. (2009). Mouse models of Fanconi anemia. Mutation Research, 668(1-2), 133-140.

40. Ode, A., Kopf, J., Kurtz, A., Schmidt-Bleek, K., Schrade, P., Kolar, P., et al. (2011). CD73 and CD29 concurrently mediate the mechanically induced decrease of migratory capacity of mesenchymal stromal cells. European Cells and Materials, 22, 26-42.

41. Pietila, M., Lehtonen, S., Tuovinen, E., Lähteenmäki, K., Laitinen, S., Leskelä, H. V., et al. (2012). CD200 positive human mesenchymal stem cells suppress TNF-alpha secretion from CD200 receptor positive macrophage-like cells. PloS One, 7(2), e31671.

42. Alvarez-Viejo, M., Menendez-Menendez, Y., Blanco-Gelaz, M. A., Ferrero-Gutierrez, A., Fernandez-Rodriguez, M. A., Gala, J., et al. (2013). Quantifying mesenchymal stem cells in the mononuclear cell fraction of bone marrow samples obtained for cell therapy. Transplantation Proceedings, 45(1), 434-439.

43. Aoyagi, K., Yamazaki, Y., Matsuo, A., Shimakura, Y., Takeda, A., \& Uchinuma, E. (2010). Significance of CD271 in bone marrow mesenchymal stem cells-changes by cryopreservation. The Journal of Craniofacial Surgery, 21(3), 666-678.

44. Raaijmakers, M. H., Mukherjee, S., Guo, S., Zhang, S., Kobayashi, T., Schoonmaker, J. A., et al. (2010). Bone progenitor dysfunction induces myelodysplasia and secondary leukaemia. Nature, 464(7290), 852-857.

45. Muruganandan, S., Roman, A. A., \& Sinal, C. J. (2009). Adipocyte differentiation of bone marrow-derived mesenchymal stem cells: cross talk with the osteoblastogenic program. Cellular and Molecular Life Sciences, 66(2), 236-253.

46. Zhou, Y., He, Y., Xing, W., Zhang, P., Shi, H., Chen, S., et al. (2017). Abnormal bone marrow microenvironment contributes to hematopoietic dysfunction in Fanconi anemia. Haematologica, 102(8), 1017-1027.

47. Yamamoto, K., Hirano, S., Ishiai, M., Morishima, K., Kitao, H., Namikoshi, K., et al. (2005). Fanconi anemia protein FANCD2 promotes immunoglobulin gene conversion and DNA repair through a mechanism related to homologous recombination. Molecular and Cellular Biology, 25(1), 34-43.
48. Chagraoui, H., Komura, E., Tulliez, M., Giraudier, S., Vainchenker, W., \& Wendling, F. (2002). Prominent role of TGF-beta 1 in thrombopoietin-induced myelofibrosis in mice. Blood, 100(10), 3495-3503.

49. Fujita, T., Epperly, M. W., Zou, H., Greenberger, J. S., \& Wan, Y. (2008). Regulation of the anaphase-promoting complex-separase cascade by transforming growth factor-beta modulates mitotic progression in bone marrow stromal cells. Molecular Biology of the Cell, 19(12), 5446-5455.

50. Letterio, J. J., Geiser, A. G., Kulkarni, A. B., Dang, H., Kong, L., Nakabayashi, T., et al. (1996). Autoimmunity associated with TGF-beta1-deficiency in mice is dependent on MHC class II antigen expression. The Journal of Clinical Investigation, 98(9), $2109-2119$.

51. Xu, C., Yu, P., Han, X., Du, L., Gan, J., Wang, Y., et al. (2014). TGF-beta promotes immune responses in the presence of mesenchymal stem cells. Journal of Immunology, 192(1), 103-109.

52. Rizzo, S., Killick, S. B., Patel, S., Ball, S. E., Wadhwa, M., Dilger, P., et al. (1999). Reduced TGF-beta1 in patients with aplastic anaemia in vivo and in vitro. British Journal of Haematology, 107(4), 797-803.

53. Wu, J., Niu, J., Li, X., Wang, X., Guo, Z., \& Zhang, F. (2014). TGF-beta1 induces senescence of bone marrow mesenchymal stem cells via increase of mitochondrial ROS production. $B M C$ Developmental Biology, 14, 21.

54. Kumari, U., Jun, Y., Bay, W. Huat, Lyakhovich, B., A (2014). Evidence of mitochondrial dysfunction and impaired ROS detoxifying machinery in Fanconi anemia cells. Oncogene, 33(2), $165-172$.

55. He, T., Quan, T., Shao, Y., Voorhees, J. J., \& Fisher, G. J. (2014). Oxidative exposure impairs TGF-beta pathway via reduction of type II receptor and SMAD3 in human skin fibroblasts. Age, 36(3), 9623.

56. Song, X., Xie, Y., Kang, R., Hou, W., Sun, X., Epperly, M. W., et al. (2016). FANCD2 protects against bone marrow injury from ferroptosis. Biochemical and Biophysical Research Communications, 480(3), 443-449. 